\title{
Association between MMP-3 and MMP-9 polymorphisms and coronary artery disease
}

\author{
OSMAN BETON $^{1}$, SERDAL ARSLAN $^{2}$, BURAK ACAR $^{3}$, NIL OZBILUM $^{4}$ and OCAL BERKAN ${ }^{5}$ \\ ${ }^{1}$ Department of Cardiology, Heart Center; ${ }^{2}$ Department of Medical Biology, Cumhuriyet University, Sivas 58140; \\ ${ }^{3}$ Department of Cardiology, Turkiye Yuksek Ihtisas Research and Training Hospital, Ankara 06100; Departments of \\ ${ }^{4}$ Molecular Biology and Genetics, and ${ }^{5}$ Cardiovascular Surgery, Heart Center, Cumhuriyet University, Sivas 58140, Turkey
}

Received August 30, 2016; Accepted October 10, 2016

DOI: $10.3892 /$ br.2016.782

\begin{abstract}
Matrix metalloproteinase (MMP)-3 and MMP-9 polymorphisms are characterized by plaque stability in coronary arteries. The aim of the current study was to investigate the $5 A / 6 A$ polymorphism in the $M M P-3$ gene and $C / T$ polymorphism in the $M M P-9$ gene in patients with coronary artery disease (CAD). The study population consisted of 400 patients who underwent coronary angiography. There were two groups consisting of 200 consecutive patients with CAD, presenting with stable angina pectoris, and 200 consecutive patients exhibiting normal coronary arteries. Two single nucleotide polymorphisms in the $M M P$ gene, $M M P-3$ and $M M P-9$, were detected using a polymerase chain reaction-restriction fragment length polymorphism assay. Mean age, gender distribution, smoking status, presence of diabetes mellitus and hypercholesterolemia were identified to be similar between the groups. One hundred and twenty seven (63.5\%) patients had hypertension in the CAD group, whereas only 55 (27.5\%) patients had hypertension in the control group $(\mathrm{P}<0.001)$. No significant difference in frequency of alleles and genotypes of $M M P-9 C \rightarrow T$ between the CAD and control groups was identified. The $5 A$ allele frequency of $M M P-3$ in the CAD group was significantly higher when compared with the control group $(\mathrm{P}<0.001$; odds ratio=2.18). The genotype frequency of $M M P-35 A / 5 A$ in the CAD group was significantly higher when compared with the controls $(\mathrm{P}=0.005)$. When compared
\end{abstract}

Correspondence to: Professor Osman Beton, Department of Cardiology, Heart Center, Cumhuriyet University, Sivas 58140, Turkey

E-mail: obeton@cumhuriyet.edu.tr

Abbreviations: CAD, coronary artery disease; CI, confidence interval; MMP, matrix metalloproteinase; OR, odds ratio; PCR, polymerase chain reaction; RFLP, restriction fragment length polymorphism

Key words: coronary artery disease, gene polymorphism, matrix metalloproteinase-3, matrix metalloproteinase-9 with the homozygous wild-type (6A/6A) genotype of the $M M P-3$ gene, the cumulative frequency of heterozygote and homozygote genotypes of the $M M P-3$ gene was significantly higher in the CAD compared with the control group $(\mathrm{P}<0.001)$. Thus, the present study demonstrated that the $5 A / 5 A$ and $6 A / 5 A+5 A / 5 A$ genotypes of the $M M P-3$ gene were associated with an increased risk of CAD.

\section{Introduction}

Atherosclerosis is characterized by a complex multi-factorial pathophysiology that is the major cause of coronary artery disease (CAD) (1). Conventional risk factors have been proposed to cause this condition; however, the genetic effect remains unexplained (1). Gene-environment interactions may be particularly important. Certain studies have investigated the associations between polymorphic variants in candidate genes and atherosclerosis. A potential suspected gene system is the matrix metalloproteinase (MMP) family that consists of N20 proteases, which functions to degrade collagens and other extracellular matrix proteins to maintain vascular homeostasis (2).

Macrophages, the primary cells of the atherosclerotic lesions, express MMPs as proteolytic enzymes that may influence rates of atherogenesis and the stability of atherosclerotic plaques (3). The rate of extracellular matrix breakdown and accumulation is predominantly regulated by the interaction between MMPs and their endogenous antagonists.

$M M P-3$ and $M M P-9$ are affected at transcription levels by two specific polymorphisms, $5 A / 6 A$ and $C / T$, respectively, with their gene promoters $(3,4)$. A common variant in the promoter region of the human $M M P-3$ gene with one allele having a run of five adenines $(5 A)$ and the other having six adenines $(6 A)$ has been reported as an important genetic risk factor for premature myocardial infarction (5), carotid stenosis (6) and in-stent restenosis (7). Another MMP is gelatinase B (MMP-9), which is characterized by a broad substrate specificity and high expression in the disruption-prone regions of atherosclerotic plaques (8). It has been reported that the $T$ allele of the $-1562 C / T$ promoter polymorphism was associated with an approximate 2-fold higher promoter activity (4).

In the current study, whether the $5 A / 6 A$ polymorphism in the $M M P-3$ gene and the $C / T$ polymorphism in the $M M P-9$ 
gene, as well as other sequence variants influenced the presence of CAD was investigated.

\section{Materials and methods}

Study population. The study group consisted of 200 consecutive patients with angiographically diagnosed CAD and 200 consecutive patients with angiographically normal coronary arteries, and the two groups were recruited from the Department of Cardiology, Cumhuriyet University Hospital (Sivas, Turkey). All patients exhibited stable symptoms. The study was conducted in accordance with the Declaration of Helsinki. The study protocol was approved by the Ethics Committee of the Medical Faculty of Cumhuriyet University (approval no. 2011-02/04) and each participant provided written informed consent.

Coronary angiography and quantitative analysis. Coronary angiography and interventional procedures were performed using standard techniques via transfemoral or transradial approaches. All imaging analyses were performed by two experienced interventional cardiologists. The diagnosis of CAD was established angiographically in the presence of $>50 \%$ stenosis in $\geq 1$ of the three major coronary arteries or their major branches, and all the patients had stable CAD. Routine intracoronary injections of nitroglycerin were administered to avoid artery spasm.

Blood samples and genotyping. All venous blood samples (2 $\mathrm{ml})$ were obtained upon patient presentation. After an overnight fast, antecubital venous blood samples $(2 \mathrm{ml})$ were collected in vacuum tubes between 08:00 and 10:00 a.m. Blood samples were brought to the Genetic Laboratory (Cumhuriyet University Hospital) within $10 \mathrm{~min}$. The DNA was extracted from the whole blood of the patient and control groups using a standard phenol-chloroform method according to Sambrook and Russell (9). The MMP-3 and $M M P-9$ genotypes were determined using polymerase chain reaction (PCR)-based restriction fragment length polymorphism (RFLP). The PCR reaction was performed in a total volume of $25 \mu \mathrm{l}$ containing $\sim 100 \mathrm{ng}$ genomic DNA, $200 \mathrm{mM}$ deoxynucleotide triphosphates (dNTPs), $0.2 \mathrm{mM}$ of each of the synthesized primers (Iontek Biotechnology, Istanbul, Turkey; Table I), $1 \mathrm{X}$ reaction buffer (MBI Fermentas, St. Leon-Rot, Germany), $1.5 \mathrm{mM} \mathrm{MgCl}_{2}$, and 2-unit Taq polymerase (MBI Fermentas). The temperature profile for the 35-cycle amplification reaction using a Techne TC-4000 thermal cycler (Techne; Bibby Scientific Ltd., Staffordshire, UK) was as follows: Initial denaturation at $94^{\circ} \mathrm{C}$ for $5 \mathrm{~min}$, denaturation at $94^{\circ} \mathrm{C}$ for $30 \mathrm{sec}$, annealing according to the temperatures in Table I and extension at $72^{\circ} \mathrm{C}$ for $1 \mathrm{~min}$, with a final extension at $72^{\circ} \mathrm{C}$ for $5 \mathrm{~min}$. Amplification products $(5 \mu \mathrm{l})$ were resolved in $2 \%$ agarose gel (Sigma-Aldrich, St. Louis, MO, USA). MMP-3 and MMP-9 PCR products $(10 \mu \mathrm{l})$ were digested with 10 units of restriction enzymes, SphI and XmnI (MBI Fermentas; Table I). The fragments and uncut products were separated using $4 \%$ agarose gel electrophoresis (45 min, $100 \mathrm{~mA}$ and $50 \mathrm{~V}$ ) and visualized on a Safe Imager ${ }^{\mathrm{TM}}$ 2.0 Blue Light Transilluminator (Thermo Fisher Scientific, Inc., Waltham, MA, USA) after staining with ethidium bromide (Fig. 1).
Statistical analysis. Statistical analysis was performed using SPSS 16.0 (SPSS, Inc., Chicago, IL, USA). The variables were investigated using the One Sample Kolmogorov-Smirnov test to establish whether there was normal distribution. Continuous variables were expressed as means \pm standard deviation or medians (minimum-maximum) in the presence of abnormal distribution, and the categorical variables were presented as percentages. Comparisons between groups of patients were made using a Pearson $\chi^{2}$ test for categorical variables, Student's t-test for normally distributed continuous variables and the Mann-Whitney $U$ test when the distribution was skewed. Odds ratio (OR) and 95\% confidence intervals (CIs) were calculated for each variable to compare the two groups. Analysis of haplotype frequencies was performed using the EH program (www.jurgott.org/linkage/eh.htm; Rockefeller University, New York, NY, USA), which assesses and estimates linkage disequilibrium between different markers or between a disease locus and markers (10). The EH program estimates allele frequencies for each marker and haplotype frequencies are estimated via allelic association. In all cases, $\mathrm{P}<0.05$ was considered to indicate a statistically significant difference.

\section{Results}

Clinical and demographic parameters. The clinical and demographic parameters of patients in the CAD and control groups are presented in Table II. The distribution of age, gender, smoking status, diabetes and hypercholesterolemia status between the CAD and control groups were not significantly different, except for hypertension (Table II). The presence of hypertension was significantly higher in the CAD group when compared with the control group (63.5 vs. $27.5 \%$; $\mathrm{P}<0.001)$.

Allelic and genotype frequencies. The allele and genotype distributions of $M M P-3$ and $M M P-9$ genes in the CAD and control groups are presented in Table III. The distribution of the $M M P-3$ allelic frequency differed significantly between the $\mathrm{CAD}$ and control groups $(\mathrm{P}<0.001 ; \mathrm{OR}=2.18)$. Comparison of the $5 A / 5 A$ genotype with the wild-type $6 A / 6 A$ genotype of the $M M P-3$ gene revealed that the variation between CAD patients and control subjects was statistically significant $(\mathrm{P}=0.005 ; \mathrm{OR}=2.92)$. Distribution of the MMP-9 gene allelic and genotype frequency was similar between the CAD and control groups (Table III).

Haplotype analysis. Haplotype analysis was conducted for all the possible haplotypes, and all four haplotypes determined by the two single nucleotide polymorphisms, were observed in the study samples. Haplotype frequencies of the MMP-3 and $M M P-9$ genes in the study population are presented in Table III. Distribution of the $5 A-C$ haplotype frequency between the CAD and control groups was statistically significant $(\mathrm{P}=0.001)$. The distributions of $6 A-C$ and $5 A-T$ haplotype frequencies were similar between the $\mathrm{CAD}$ and control groups $(\mathrm{P}=0.896$ and $\mathrm{P}=0.152$, respectively; Table IV).

Risk estimates with regards to the demographic and clinical parameters. The risk estimates of the $M M P-3$ polymorphisms were calculated for the demographic and clinical parameters, and are presented in Table V. As the allele and genotype 
Table I. Primer sequences, annealing temperatures and restriction enzymes of two polymorphisms.

\begin{tabular}{llcr}
\hline Polymorphism & \multicolumn{1}{c}{ Primer sequence } & Annealing temperature $\left({ }^{\circ} \mathrm{C}\right)$ & Restriction enzyme \\
\hline MMP-9 & F: 5'-GCCTGGCACATAGTAGGCCC-3' & 56 & SphI \\
-1562 C $>$ T & R: 5'-CTTCCTAGCCAGCCGGCATC-3' & 53 & $X m n I$ \\
MMP-3 & F: 5'-GATTACAGACATGGGTCACA-3' & & \\
$-16125 \mathrm{~A} / 6 \mathrm{~A}$ & R: 5'-TTTCAATCAGGACAAGACGAAGTTT-3' & \\
\hline
\end{tabular}

MMP, matrix metalloproteinase; F, forward; R, reverse.
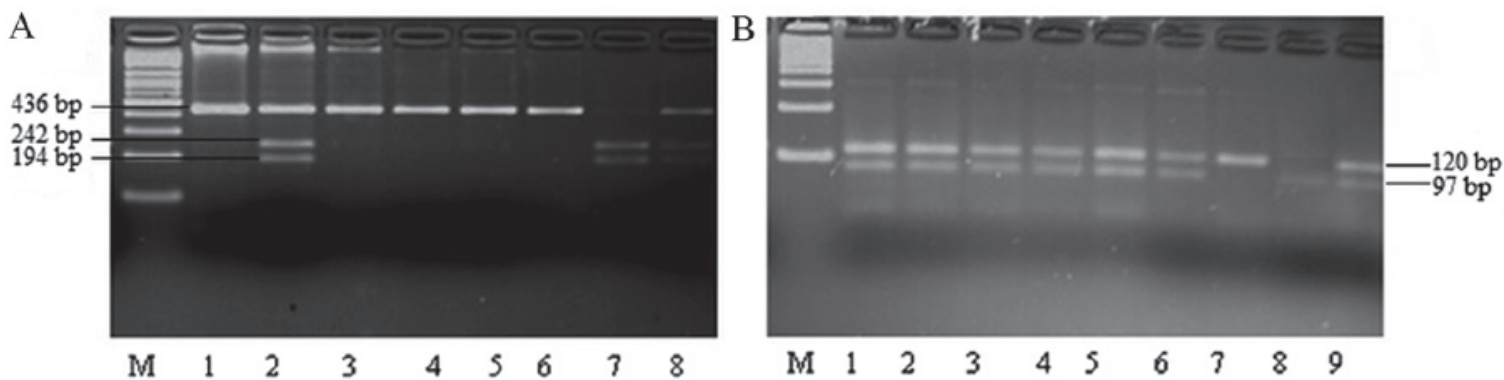

Figure 1. PCR-RFLP analysis of the $M M P-3$ and $M M P-9$ genes. (A) PCR-RFLP analysis of the MMP-9 gene: CC genotype 436 bp (lanes 1 and 3-6); CT genotype 436, 242 and 194 bp (lanes 2 and 8); and TT genotype 242 and 194 bp (lane 7). Lane M, molecular weight marker (100 bp). (B) PCR-RFLP analysis of the MMP-3 gene: 6A/6A genotype $120 \mathrm{bp}$ (lane 7); 6A/5A genotype 120, 97 and 23 bp (lanes 1-6 and 9); and 5A/5A genotype 97 and 23 bp (lane 8). Lane M, molecular weight marker (100 bp). PCR-RFLP, polymerase chain reaction-restriction fragment length polymorphism; MMP, matrix metalloproteinase.

frequencies of $M M P-9$ were not statistically significant, the same calculations for risk estimation were not performed for the MMP-9 polymorphisms. Female patients in the CAD group exhibited significantly higher frequencies of the $6 A / 5 A$ genotype compared with the female patients in the control group $(\mathrm{P}<0.001 ; \mathrm{OR}=4.59)$. The male patients in the CAD group demonstrated statistically higher frequencies of $6 A / 5 A$ and $5 A / 5 A$ genotypes compared with the male patients in the control group $[\mathrm{P}=0.001(\mathrm{OR}=1.98)$ and $\mathrm{P}=0.035$ $(\mathrm{OR}=2.51)$, respectively]. Current smokers in the CAD group demonstrated a higher frequency of the $6 \mathrm{~A} / 5 \mathrm{~A}$ genotype compared with current smokers in the control group $(\mathrm{P}=0.001$; $\mathrm{OR}=2.81$ ). When compared with the control subjects, CAD patients with hypertension had significantly higher frequencies of the $6 A / 5 A$ and $5 A / A$ genotypes $[\mathrm{P}=0.003(\mathrm{OR}=2.78)$ and $\mathrm{P}=0.006(\mathrm{OR}=10.23)$, respectively]. Patients with hypercholesterolemia in the CAD group had statistically different frequencies of $6 A / 5 A$ and $5 A / 5 A$ genotypes compared with the control subjects with hypercholesterolemia $[\mathrm{P}=0.016$ $(\mathrm{OR}=2.48)$ and $\mathrm{P}=0.025(\mathrm{OR}=8.69)$, respectively; Table V].

\section{Discussion}

In the present study, the associations between CAD and $M M P-3$ and $M M P-9$ polymorphisms were investigated. The patients with $\mathrm{CAD}$ exhibited a higher frequency of the $5 A$ allele, $5 A / 5 A$ genotype and $6 A / 5 A+5 A / 5 A$ genotype of the $M M P-3$ gene compared with the patients with normal coronary arteries. The distribution of allele and genotype frequencies of the MMP-9 gene was similar between the CAD and control groups. However, there was a strong link between the CAD groups as compared to patients with normal coronary arteries in terms of $5 A-C$ haplotype of the $M M P-3$ and $M M P-9$ genes.

Stromelysin-1, also termed MMP-3, catalyses the breakdown of extracellular matrix macromolecules, including proteoglycans, different types of collagen, fibronectin, and laminin, and facilitates the conversion of other MMPs, such as collagenase-1 (MMP-1), collagenase-2 (MMP-8), matrilysin (MMP-7), and 92-kDa gelatinase (MMP-9), from their inactive to their proteolytically active forms (11). The human stromelysin-1 gene contains a common promoter polymorphism, characterized by runs of five or six adenosines, located at nucleotide positions $1171-1175$ or $1171-1176$, respectively, upstream from the start site of transcription (11). Its expression is primarily regulated at the level of transcription 5. Due to its important function in extracellular matrix turnover, stromelysin-1 polymorphism 5A/6A was extensively investigated in patients with CAD (12).

An association between the $M M P-35 A / 6 A$ promoter polymorphism and atherosclerosis was first described in 1995, and the $6 A / 6 A$ genotype was associated with greater progression of coronary atherosclerosis (13). It was shown that the $6 A / 6 A$ genotype was associated with a greater progression of CAD following angioplasty (14). Regarding MMP-3, certain studies have linked the $6 \mathrm{~A}$ allele to a higher risk of rapid progression of the atherosclerotic process $(15,16)$. Three independent studies have found that the patients carrying the 6A/6A genotype exhibited more progression of angiographically detectable lesions in documented CAD $(13,15)$. However, this association was not supported by clinical studies investigating stent restenosis subsequent to angioplasty and $M M P-3$ gene polymorphisms (11). 
Table II. Demographic and clinical parameters of patients with CAD and control subjects.

\begin{tabular}{|c|c|c|c|c|}
\hline Variable & CAD group $(n=200)$ & Control group $(n=200)$ & Odds ratio $(95 \% \mathrm{CI})$ & P-value \\
\hline Age, years & $60.2 \pm 7.4$ & $58.3 \pm 7.7$ & & 0.059 \\
\hline \multicolumn{5}{|l|}{ Gender } \\
\hline Female, n (\%) & $65(32.5)$ & $83(41.5)$ & & \\
\hline Male, n (\%) & $135(67.5)$ & $117(58.5)$ & $1.67(0.98-2.87)$ & 0.058 \\
\hline \multicolumn{5}{|l|}{ Smoking status } \\
\hline Non-smoker, n (\%) & $98(49.0)$ & $113(56.5)$ & & \\
\hline Smoker, n (\%) & $102(51.0)$ & $87(43.5)$ & $1.35(0.91-2.00)$ & 0.133 \\
\hline \multicolumn{5}{|l|}{ Hypertension } \\
\hline Absent, n (\%) & $73(36.5)$ & $145(72.5)$ & & \\
\hline Present, n (\%) & $127(63.5)$ & $55(27.5)$ & $4.58(3.00-7.00)$ & $<0.001$ \\
\hline \multicolumn{5}{|l|}{ Diabetes mellitus } \\
\hline Absent, n (\%) & $121(60.5)$ & $131(65.5)$ & & \\
\hline Present, n (\%) & $79(39.5)$ & $69(34.5)$ & $1.24(0.82-1.86)$ & 0.300 \\
\hline \multicolumn{5}{|l|}{ Hypercholesterolemia } \\
\hline Absent, n (\%) & $128(64.0)$ & $145(72.5)$ & & \\
\hline Present, n (\%) & $72(36.0)$ & $55(27.5)$ & $1.48(0.97-2.26)$ & 0.068 \\
\hline
\end{tabular}

CAD, coronary artery disease; $\mathrm{CI}$, confidence interval.

Table III. Risk estimates of alleles and genotypes for MMP polymorphisms in the two study populations.

\begin{tabular}{|c|c|c|c|c|}
\hline Gene & CAD group, n (\%) & Control group, n (\%) & OR $(95 \% \mathrm{CI})$ & P-value \\
\hline \multicolumn{5}{|l|}{$M M P-3$} \\
\hline $6 \mathrm{~A}$ & $269(67.3)$ & $327(81.8)$ & Reference $^{\mathrm{a}}$ & - \\
\hline $5 \mathrm{~A}$ & $131(32.8)$ & $73(18.3)$ & $2.18(1.57-3.03)$ & $<0.001$ \\
\hline $6 \mathrm{~A} / 6 \mathrm{~A}$ & $90(45.0)$ & $138(69.0)$ & Reference $^{\mathrm{a}}$ & - \\
\hline $6 \mathrm{~A} / 5 \mathrm{~A}$ & $89(44.5)$ & $51(25.5)$ & $0.97(0.55-1.72)$ & 0.929 \\
\hline $5 \mathrm{~A} / 5 \mathrm{~A}$ & $21(10.5)$ & $11(5.5)$ & $2.92(1.34-6.36)$ & 0.005 \\
\hline $6 \mathrm{~A} / 5 \mathrm{~A}+5 \mathrm{~A} / 5 \mathrm{~A}$ & $110(55.0)$ & $62(3.1)$ & $2.72(1.80-4.09)$ & $<0.001$ \\
\hline \multicolumn{5}{|l|}{$M M P-9$} \\
\hline $\mathrm{C}$ & $354(88.5)$ & $351(87.8)$ & Reference $^{\mathrm{a}}$ & - \\
\hline $\mathrm{T}$ & $46(11.5)$ & 49 (12.3) & $0.93(0.60-1.42)$ & 0.743 \\
\hline $\mathrm{CC}$ & $158(79.0)$ & $154(77.0)$ & Reference $^{\mathrm{a}}$ & - \\
\hline $\mathrm{CT}$ & $38(19.0)$ & $43(21.5)$ & $0.86(0.52-1.40)$ & 0.550 \\
\hline TT & $4(2.0)$ & $3(1.5)$ & $1.30(0.28-5.90)$ & 0.517 \\
\hline $\mathrm{CT}+\mathrm{TT}$ & $42(21.0)$ & $46(23.0)$ & $0.89(0.55-1.42)$ & 0.629 \\
\hline
\end{tabular}

${ }^{a}$ Wild-type allele or genotype served as a reference. CAD, coronary artery disease; CI, confidence interval; MMP, matrix metalloproteinase; OR, odds ratio.

Among the MMPs that are expressed in atheroma is $M M P-3$, which has a broad substrate specificity and activates other enzymes in the MMP family (5). In various cross-sectional studies investigating patients with angiographically documented CAD, it was demonstrated that patients with the $6 \mathrm{~A} / 6 \mathrm{~A}$ genotype have more coronary arteries with significant stenosis when compared with those of the $5 A / 5 A$ or $5 A / 6 A$ genotype $(5,17,18)$. However, in the present study, $5 A / 5 A$ and $6 A / 5 A+5 A / 5 A$ genotypes were demonstrated to be strongly associated with CAD.

The expression of $M M P-9$ is regulated primarily at the transcription level, and it was investigated in studies associated with CAD. Zhang et al (4) reported a functional $21562 \mathrm{C} / \mathrm{T}$ polymorphism in the promoter region of $M M P-9$. The $T$ allele was found to be associated with complicated coronary lesions, and carriers of the $T$ allele demonstrated greater levels of the 
Table IV. Frequencies of alleles and genotypes for MMP polymorphisms in the two study populations.

\begin{tabular}{lcccc}
\hline \multicolumn{2}{l}{ Frequency of haplotypes } & & & \\
\hline MMP-3 & MMP-9 & CAD group, n (\%) & Control group, n (\%) & OR (95\% CI) \\
\hline $6 \mathrm{~A}$ & $\mathrm{C}$ & $117(29.3)$ & $144(36.0)$ & Reference $^{\mathrm{a}}$ \\
$6 \mathrm{~A}$ & $\mathrm{~T}$ & $17(4.3)$ & $20(5.0)$ & $1.04(0.52-2.08)$ \\
5A & $\mathrm{C}$ & $58(14.5)$ & $32(8.0)$ & $2.23(1.35-3.66)$ \\
$5 \mathrm{~A}$ & $\mathrm{~T}$ & $8(2.0)$ & $4(1.0)$ & $2.46(0.72-8.37)$ \\
\hline
\end{tabular}

${ }^{a}$ Wild-type allele or genotype served as a reference. CAD, coronary artery disease; CI, confidence interval; MMP, matrix metalloproteinase; OR, odds ratio.

Table V. Risk estimates for $M M P-3$ polymorphisms in demographic and clinical parameters.

\begin{tabular}{|c|c|c|c|c|}
\hline Variable & CAD group, $\mathrm{n}(\%)$ & Control group, n (\%) & Odds ratio $(95 \% \mathrm{CI})$ & P-value \\
\hline \multicolumn{5}{|l|}{ Female } \\
\hline $6 \mathrm{~A} / 6 \mathrm{~A}$ & $36(55.4)$ & $70(84.3)$ & Reference $^{\mathrm{a}}$ & - \\
\hline $6 \mathrm{~A} / 5 \mathrm{~A}$ & $26(40.0)$ & $11(13.3)$ & $4.59(2.04-10.34)$ & $<0.001$ \\
\hline $5 \mathrm{~A} / 5 \mathrm{~A}$ & $3(4.6)$ & $2(2.4)$ & $2.91(0.46-18.25)$ & 0.342 \\
\hline \multicolumn{5}{|l|}{ Male } \\
\hline $6 \mathrm{~A} / 6 \mathrm{~A}$ & $54(40.0)$ & $68(58.1)$ & Reference $^{\mathrm{a}}$ & - \\
\hline $6 \mathrm{~A} / 5 \mathrm{~A}$ & $63(46.7)$ & $40(34.2)$ & $1.98(1.16-3.38)$ & 0.011 \\
\hline $5 \mathrm{~A} / 5 \mathrm{~A}$ & $18(13.3)$ & $9(7.7)$ & $2.51(1.04-6.04)$ & 0.035 \\
\hline \multicolumn{5}{|l|}{ Smoker } \\
\hline $6 \mathrm{~A} / 6 \mathrm{~A}$ & $44(43.1)$ & $58(66.7)$ & Reference $^{\mathrm{a}}$ & - \\
\hline $6 \mathrm{~A} / 5 \mathrm{~A}$ & $47(46.1)$ & $22(25.3)$ & $2.81(1.48-5.34)$ & 0.001 \\
\hline $5 \mathrm{~A} / 5 \mathrm{~A}$ & $11(10.8)$ & $7(8.0)$ & $2.07(0.74-5.77)$ & 0.158 \\
\hline \multicolumn{5}{|c|}{ Hypertension } \\
\hline $6 \mathrm{~A} / 6 \mathrm{~A}$ & $52(41.0)$ & $38(69.1)$ & Reference $^{\mathrm{a}}$ & - \\
\hline $6 \mathrm{~A} / 5 \mathrm{~A}$ & $61(48.0)$ & $16(29.1)$ & $2.78(1.39-5.56)$ & 0.003 \\
\hline $5 \mathrm{~A} / 5 \mathrm{~A}$ & $14(11.0)$ & $1(1.8)$ & $10.23(1.28-81.19)$ & 0.006 \\
\hline \multicolumn{5}{|c|}{ Diabetes mellitus } \\
\hline $6 \mathrm{~A} / 6 \mathrm{~A}$ & $40(50.6)$ & $44(63.8)$ & Reference $^{\mathrm{a}}$ & - \\
\hline $6 \mathrm{~A} / 5 \mathrm{~A}$ & $32(40.5)$ & $20(29.0)$ & $1.76(0.87-3.55)$ & 0.114 \\
\hline $5 \mathrm{~A} / 5 \mathrm{~A}$ & $7(8.9)$ & $5(7.2)$ & $1.54(0.45-5.24)$ & 0.487 \\
\hline \multicolumn{5}{|c|}{ Hypercholesterolemia } \\
\hline $6 \mathrm{~A} / 6 \mathrm{~A}$ & $29(40.3)$ & $36(65.5)$ & Reference $^{\mathrm{a}}$ & - \\
\hline $6 \mathrm{~A} / 5 \mathrm{~A}$ & $36(50.0)$ & $18(32.7)$ & $2.48(1.17-5.24)$ & 0.016 \\
\hline $5 \mathrm{~A} / 5 \mathrm{~A}$ & $7(9.7)$ & $1(1.8)$ & $8.69(1.01-74.71)$ & 0.025 \\
\hline
\end{tabular}

${ }^{a}$ Wild-type allele or genotype served as a reference. CAD, coronary artery disease; CI, confidence interval; MMP, matrix metalloproteinase; Ref, reference.

MMP-9 mRNA protein, as well as stiffer, large arteries (1). Consistent with the result reported by Blankenberg et al (19), the present study found that the $M M P-9 C / T$ polymorphism is not associated with an increased risk of CAD.

A previous study suggested that haplotype analysis is frequently more powerful than analysis using single polymorphisms (20). In the current study, an association between the $5 A-C$ haplotype and an increased risk of CAD was identified.
There were certain limitations of the present study. The serum levels of MMP-3 and MMP-9 were not measured. In addition, although the study subjects were recruited prospectively, this study was a case-control study and selection bias was not excluded. Furthermore, clinical outcomes of the present findings were not investigated. Therefore, large-scale, multicenter randomized clinical studies are required to assess the effect of the $M M P-3$ polymorphism on clinical 
cardiovascular outcomes. In conclusion, the present study demonstrated that the $5 A / 5 A$ and $6 A / 5 A+5 A / 5 A$ alleles and the $5 A-C$ haplotype of the $M M P-3 / M M P-9$ genes were associated with an increased risk of CAD.

\section{Acknowledgements}

The present study was supported by the Research Council of Cumhuriyet University (Sivas, Turkey; CUBAP project no. F-340).

\section{References}

1. Abilleira S, Bevan S and Markus HS: The role of genetic variants of matrix metalloproteinases in coronary and carotid atherosclerosis. J Med Genet 43: 897-901, 2006

2. Chen QJ, Lu L, Peng WH, Hu J, Yan XX, Wang LJ, Zhang Q, Zhang RY and Shen WF: Polymorphisms of MMP-3 and TIMP-4 genes affect angiographic coronary plaque progression in non-diabetic and type 2 diabetic patients. Clin Chim Acta 405 97-103, 2009.

3. Ye S, Gale CR and Martyn CN: Variation in the matrix metalloproteinase-1 gene and risk of coronary heart disease. Eur Heart J 24: 1668-1671, 2003.

4. Zhang B, Ye S, Herrmann SM, Eriksson P, de Maat M, Evans A Arveiler D, Luc G, Cambien F, Hamsten A, et al: Functional polymorphism in the regulatory region of gelatinase B gene in relation to severity of coronary atherosclerosis. Circulation 99 1788-1794, 1999.

5. Beyzade S, Zhang S, Wong YK, Day IN, Eriksson P and Ye S: Influences of matrix metalloproteinase-3 gene variation on extent of coronary atherosclerosis and risk of myocardial infarction. J Am Coll Cardiol 41: 2130-2137, 2003.

6. Rauramaa R, Väisänen SB, Luong LA, Schmidt-Trücksäss A, Penttilä IM, Bouchard C, Töyry J and Humphries SE: Stromelysin-1 and interleukin-6 gene promoter polymorphisms are determinants of asymptomatic carotid artery atherosclerosis. Arterioscler Thromb Vasc Biol 20: 2657-2662, 2000.

7. Liu PY, Li YH, Chan SH, Lin LJ, Wu HL, Shi GY and Chen JH: Genotype-phenotype association of matrix metalloproteinase-3 polymorphism and its synergistic effect with smoking on the occurrence of acute coronary syndrome. Am J Cardiol 98: 1012-1017, 2006.

8. Johnson C and Galis ZS: Matrix metalloproteinase-2 and -9 differentially regulate smooth muscle cell migration and cell-mediated collagen organization. Arterioscler Thromb Vasc Biol 24: 54-60, 2004.
9. Sambrook J and Russell DW: Purification of nucleic acids by extraction with phenol: chloroform. CSH Protoc 2006: pii: pdb. prot $4455,2006$.

10. Xie X and Ott J: Testing linkage disequilibrium between a disease gene and marker loci. Am J Hum Genet 53: 1107-1113, 1993.

11. Hoppmann P, Koch W, Schömig A and Kastrati A: The 5A/6A polymorphism of the stromelysin-1 gene and restenosis after percutaneous coronary interventions. Eur Heart J 25: 335-341, 2004.

12. Koch W, de Waha A, Hoppmann P, Schömig A and Kastrati A: Haplotypes and $5 \mathrm{~A} / 6 \mathrm{~A}$ polymorphism of the matrix metalloproteinase-3 gene in coronary disease: Case-control study and a meta-analysis. Atherosclerosis 208: 171-176, 2010.

13. Ye S, Watts GF, Mandalia S, Humphries SE and Henney AM: Preliminary report: Genetic variation in the human stromelysin promoter is associated with progression of coronary atherosclerosis. Br Heart J 73: 209-215, 1995.

14. Humphries S, Bauters C, Meirhaeghe A, Luong L, Bertrand M and Amouyel P: The 5A6A polymorphism in the promoter of the stromelysin-1 (MMP3) gene as a risk factor for restenosis. Eur Heart J 23: 721-725, 2002.

15. de Maat MP, Jukema JW, Ye S, Zwinderman AH, Moghaddam PH, Beekman M, Kastelein JJ, van Boven AJ, Bruschke AV, Humphries SE, et al: Effect of the stromelysin-1 promoter on efficacy of pravastatin in coronary atherosclerosis and restenosis. Am J Cardiol 83: 852-856, 1999.

16. Humphries SE, Luong LA, Talmud PJ, Frick MH, Kesäniemi YA, Pasternack A, Taskinen MR and Syvänne M: The 5A/6A polymorphism in the promoter of the stromelysin-1 (MMP-3) gene predicts progression of angiographically determined coronary artery disease in men in the LOCAT gemfibrozil study. Lopid Coronary Angiography Trial. Atherosclerosis 139: 49-56, 1998.

17. Hirashiki A, Yamada Y, Murase Y, Suzuki Y, Kataoka H, Morimoto Y, Tajika T, Murohara T and Yokota M: Association of gene polymorphisms with coronary artery disease in low- or high-risk subjects defined by conventional risk factors. J Am Coll Cardiol 42: 1429-1437, 2003.

18. Schwarz A, Haberbosch W, Tillmanns H and Gardemann A: The stromelysin-1 5A/6A promoter polymorphism is a disease marker for the extent of coronary heart disease. Dis Markers 18: 121-128, 2002.

19. Blankenberg S, Rupprecht HJ, Poirier O, Bickel C, Smieja M, Hafner G, Meyer J, Cambien F and Tiret L; AtheroGene Investigators: Plasma concentrations and genetic variation of matrix metalloproteinase 9 and prognosis of patients with cardiovascular disease. Circulation 107: 1579-1585, 2003.

20. Johnson GC, Esposito L, Barratt BJ, Smith AN, Heward J, Di Genova G, Ueda H, Cordell HJ, Eaves IA, Dudbridge F, et al: Haplotype tagging for the identification of common disease genes. Nat Genet 29: 233-237, 2001. 